\title{
Reply to the Letter by Uzun and Pehlivan Entitled 'Characteristics of Hyperautofluorescent Choroidal Vessels within the Macular Atrophic Area Using Spectral-Domain Optical Coherence Tomography'
}

\author{
Ari Shinojima Ryusaburo Mori Hiroyuki Nakashizuka Akiyuki Kawamura \\ Department of Ophthalmology, School of Medicine, Nihon University, Tokyo, Japan
}

Mitsuko Yuzawa

We thank Dr. Uzun and Dr. Pehlivan for their interest in our article [1]. Our research data were obtained, in part, from the detailed medical records of all 43 patients studied. There were no pregnant patients, and the menstrual cycle status of the female patients was not considered in this study. No patients with strabismus were included in our study.

Sleep, exercise, smoking, and consumption of alcohol or drinks with/without caffeine, as well as body mass indexes, and systemic blood pressure have all been reported to significantly affect choroidal thickness (CT) measurements [2,3] as Drs. Uzun and Pehlivan suggested [1].

In the group with hyperautofluorescent choroidal vessels on fundus autofluorescence (group 1, 17 patients), we confirmed the presence of the following factors: smoking in 3 men (17.6\%); consumption of alcohol in 3 men (17.6\%); hypertension in 8 patients ( 5 men, 3 women) (47.1\%); hyperlipidemia in 2 women (11.8\%), and vasculopathies in 3 patients ( 1 man, 2 women) $(17.6 \%)$. In the group without hyperautofluorescent choroidal vessels on fundus autofluorescence (group 2, 26 patients), we confirmed the presence of the following factors: smoking in 7 patients ( 5 men, 2 women) (26.9\%); consumption of alcohol in 2 men $(7.7 \%)$; hypertension in 4 patients
(2 men, 2 women) (15.4\%); hyperlipidemia in 2 men (7.7\%); diabetes mellitus in 2 men (7.7\%); vasculopathies in 2 women $(7.7 \%)$, and glaucoma in 3 men (11.5\%). We did not obtain data pertaining to sleep patterns, exercise, consumption of drinks with/without caffeine, or body mass indexes.

As to arteriosclerosis risk factors, such as hypertension, smoking, diabetes mellitus, and hyperlipidemia [4], there were 10 such patients $(58.8 \%)$ in group 1 and 11 $(42.3 \%)$ in group 2 . There were no significant differences between these two groups $(\mathrm{p}=0.51)$.

Refractive error and intraocular pressure were $-1.8 \pm 3.4$ diopters and $13.6 \pm 3.2$ $\mathrm{mm} \mathrm{Hg}$ in group 1 , and $-2.0 \pm 3.9$ diopters and $14.3 \pm 3.1 \mathrm{~mm} \mathrm{Hg}$ in group 2, respectively. There were no significant differences between the two groups ( $p=0.83$ in refractive error, $\mathrm{p}=0.42$ in intraocular pressure).

Diurnal variation and time course also reportedly affect CT $[3,5]$, but we captured the fundus autofluorescence and optical coherence tomographic images in succession on the same day, such that they would be unlikely to seriously affect CT with or without hyperautofluorescent choroidal vessels on fundus autofluorescence.
We are now studying the issue pertaining to the relationships between axial length and hyperautofluorescent choroidal vessels. We hope to provide precise information on this topic in the near future.

\section{References}

Uzun S, Pehlivan E: Characteristics of hyperautofluorescent choroidal vessels within the macular atrophic area using spectral-domain optical coherence tomography. Ophthalmologica 2016, DOI: 10.1159/000447546.

-2 Tan KA, Gupta P, Agarwal A, Chhablani J, Cheng CY, Keane PA, Agrawal R: State of science: choroidal thickness and systemic health. Surv Ophthalmol 2016, Epub ahead of print.

-3 Nickla DL, Wallman J: The multifunctional choroid. Prog Retin Eye Res 2010;29:144168

4 Chambless LE, Heiss G, Folsom AR, Rosamond W, Szklo M, Sharrett AR, Clegg LX: Association of coronary heart disease incidence with carotid arterial wall thickness and major risk factors: the Atherosclerosis Risk in Communities (ARIC) Study, 1987-1993. Am J Epidemiol 1997;146:483-494.

5 Tan CS, Ouyang Y, Ruiz H, Sadda SR: Diurnal variation of choroidal thickness in normal, healthy subjects measured by spectral domain optical coherence tomography. Invest Ophthalmol Vis Sci 2012;53:261-266.

\section{KARGER}

(c) 2016 S. Karger AG, Basel 